\title{
MEMóRIA HISTORICA
}

\section{DEPOIMENTO DE PESSOAS, GENTE MESMO.}

\section{MARIA REGINA}

\author{
"... Constantemente as pessoas se fazem per- \\ guntas e, em seguida, voltando-se para o passado, \\ perguntam-se: "Como as cousas se passaram \\ outrora?"
}

(Fernand Braudel) (*).

Desafio que este periódico, nascido sob a inspiração do mestre Braudel, se propõe a veicular. Com uma série de depoimentos espontâneos, sejam nos escritos, preservados, sejam em conversas informais.

Não se tem, por ora, coordenadas de estruturas seletivas. Desde que sejam respostas, ou tentativas de respostas à curiosidade d'aqueles que ainda gostam de fazer perguntas.

Para o primeiro elo de uma eventual corrente, fragmentos do dia a dia, tivemos que fazer uma escolha. Capturar a história de uma vida bem presente. De um grupo social sintonizado no tempo presente, focamos a Autobiografia que Custódio Lustosa escreveu aos 85 anos.

Quanto à transcrição, uma obstinada ressalva de membros da família Lustosa. Argumentavam com a inexistência de fatos extraordinários, ao longo de uma existência calma, tranqüila tanto no trabalho profissionalizante, como na intimidade do lar. Ainda, a singeleza dos "escritos" reconhecidamente incompletos, sem notas elucidativas e suporte instrumental. Contra-argumentando, conseguiu-se o placet para uma primeira publicação. Registre-se que opta-

(*). - Entrevista com Fernand Braudel, o historiador do cotidiano, in Revista de História, São Paulo, XLI (93), 232; jan.-mar. 1972. 
mos por uma transcrição textual, tal qual as outras poucas cópias, distribuidas aos filhos, de uma numerosa, de uma bela família de gente mesmo.



(Belo Horizonte, 12 de outubro de 1959).

Nasci em S. João del-Rei em 26 de abril de 1874.

Foram meus pais o Dr. João Batista Pimental Lustosa e D. Delfina Eugênia de Almeida Lustosa.

Foram meus avós maternos o Cel. Sabino de Almeida Magalhães e D. Delfina Leocádia Leite Magalhães. O sobrenome Leite está indicando que ela pertencia à família Teixeira Leite.

Foram meus avós paternos o Cirurgião-Mór Joaquim Lustosa de Macedo e D. Rita Pimentel Lustosa.

Residiam êles em São Gonçalo do Sapucahy, ao passo que meus avós maternos residiam em São João del-Rei, em um grande sobrado que hoje pertence a meu irmão Paulo.

Eramos 12 irmãos. Destes um morreu em menoridade (o Artur) e outro (o Luiz) faleceu com 22 anos (salvo êrro):

O mais velho dos irmãos formou-se pela Escola de Minas (Ouro Preto) e foi o grande impulsionador da extração de manganês em Lafaiete (Morro da Mina).

O $2^{\circ}$ (Dr. Sabino Lustosa) formou-se em direito, foi Promotor em S. João đel-Rei e Juiz de Direito em Patos, Dores do Indaiá e Lavras. Faleceu como Desembargador aposentado em 20 de setembro de 1959: Viveu muito mais para o próximo do que para si mesmo.

O $39 \cdot$ (João) foi comerciante no Rio e tornou-se proprietário da Casa Leuzinger .

O $4^{\circ}$ dos filhos (Custódio) é o que escreve estas linhas.

(**). - Custódio de Almeida Lustosa nasceu em São João del Rei, aos 26 de abril de 1874, no bicentenário do Solar dos Lustosas, sito à Praça Embaixador Gastão da Cunha, 54 - e faleceu em Belo Horizonte, aos 3 de setembrc de 1970, em sua própria residência, rua Piauí, 1217 . 
Vem depois Laura (Irmã de Caridade). Artur, Luiz, Adelina, Carlos, Antônio (atual arcebispo do Ceará) Paulo e Maria.

Deles os mais conhecidos (além do Joaquim) são D. Antônio, Carlos (o pioneiro da ortodontia no Brasil e. Paulo, o industrial da "Cêra Dr: Lustosa" medicamento contra dor de dentes.

\section{FATOS DA MENINICE.}

O fato que mais me impressionou em minha meninice, foi a chegada do comboio da Estrada de Ferro Oeste de Minas a S. João del-Rei.

O trem de ferro havia parado nas "Oficinas" a 200 metros da Estação. Nessa parada tomaram lugar no limpa trilhos meu tio Sabino Magalhães (que possuia grande parte das ações da Companhia), o Dr. Aureliano Mourão (que obtivera a concessão) e o Dr. Paulo Freitas de Sá, o construtor da ferrovia.

A pequena locomotiva me pareceu uma coisa monstruosa, verdadeira maravilha.

No carro de luxo vinha a família Imperial e o Ministério. Estavam programadas grandes festas; foram porém, reduzidas por haver morrido em viagem o Ministro Buarque de Macedo.

A inauguração se deu em 1881, ano em que nasceu meu mano Carlos.

Minha impressão aumentou quando vi muitos carros puxados por bonitos cavalos.

As ruas do percurso estavam cobertas de folhagens. A família Imperial hospedou-se no palacete da Baronesa de São João del-Rei. O imperador visitou a cadeia, escolas e colégios. Fez depois, em companhia da Imperatriz (D. Teresa Cristina) um passeio a pé pelas principais ruas da cidade. Grande multidấo os acompanhava.

Lembro-me de que vinha na comitiva imperial o Barão de Macaubas (Dr. Abílio Borges) que tinha excelente colégio em Barbacena.

Em São João conheceu o Imperador, o professor Aureliano Pimentel que depois foi reitor do Colégio Pedro $2^{\circ}$ (no Rio) e catedrático de Português (por concurso).

\section{COLEGIO PEDRO $2^{\circ}$.}

Em 1886, sendo Reitor do Internato do Colégio Pedro $2{ }^{\circ}$ o nosso parente professor Aureliano Pimentel, propós ele, a meu pai, mandar-me para o Co- 
légio. A proposta foi aceita e tratei de me preparar para o exame liminar. Fiquei amendrontado ao tomar conhecimento do programa. Afinal segui para - Rio. Entrou comigo, no mesmo dia do exame, um neto do Visconde de Mamoré, Ministro do Império. Feitas as provas, o examinador (Dr. Carlos de Laet) apresentou-as a $D$. Pedro que se dava ao trabalho de assistir até aos exames iniciais.

Sua Majestade leu a minha prova, achou-a regular e disse que eu me poderia matricular. Leu em seguida a prova do outro aluno e, apesar de saber que era neto do Visconde de Mamoré, declarou que o rapaz devia voltar ao curso primário.

\section{O tempora, ó mores!}

Lá me matriculei no $1^{0}$ ano e estou certo de não ter feito má figura.

\section{INCIDENTE.}

No 39 dia de Colégio o professor de música desenhou uma pauta com algumas notas e mandou que eu solfejasse. Fiz ver que entrara, havia pouco, no Colégio e que nem siquer conhecia as notas. Não fui atendido e sofri o castigo de ficar de joelhos. Isto me revoltou a tal ponto que nunca mais pude estudar música. Aliás tendo tido boas notas em outras aulas, entendi-me com - Vice-reitor (Dr. Paranhos de Macedo) e fui dispensado da aula de música.

\section{NOTAS.}

O nosso curso naquele témpo era de sete anos. Havia em média, quatro exames por ano, o que faz úm total de 28. Desses 28 exames, 24 foram de distinção e 4 de nota plena. Parece gabolice, mas consultem o meu curriculum no arquivo do externato (1892) verão que não há nenhuma gabolice. As duas plenas do último ano foram até bondosas. Nesse ano eu acumulei o estudo do Cólégio com o $1^{9}$ ano da Faculdade de Direito. Daí o prejuizo de ambos os lados. Tirei afinal uma folha limpa nem reprovação nem nota simples.

\section{ACADEMIA .}

O $1^{9}$ ano da Academia (Faculdade de Direito, dirigida por Afonso Celso, no Rio) foi um tempo difícil. Meu pai havia falecido em 9 de agosto de 1890 e, porisso, o dinheiro era muito pouco. Obtive hospedagem na Casa Soto Maior, por influência de meu tio Carlos Cunha - que fora $1^{\circ}$ caixeiro da casa. Naquele tempo as casas comerciais hospedavam os fregueses do Interior. Não foi possível dar-me um quarto em separado. Eu fazia, portanto os meus estudos na Biblioteca Nacional (então na rua do Passeio). Todas as tardes fazia eu o percurso da rua Visconde de Inhauma até a rua do Passeio. 
Aí, na Biblioteca, traduzi alguma cousa de Xenofonte, li a História do Brasil de Varnhagem, apreciei a Sociologia de Spencer e a Enciclopédia Jurídica de Belame além do Droit Pur. Consegui afinal aprovação plena e, no ano seguinte, transferi-me para a Faculdade de Ouro Preto.

No Colégio a melhor nota que obtive foi em francês - distinção com louvor.

\section{FACULDADE DE OURO PRETO.}

Em Ouro Preto já estudava, na Escola de Minas, meu mano Joaquim. As famílias Ouropretanas recebiam muito bem os estudantes. Assim é que pudemos frequientar as casas Walter Helbulk, Burzelm Bhering e a casa do Dr. Téffilo Ribeiro a quem fomos recomendados por meu tio Eduardo Magalhães. Em Ouro Preto morei em uma república cuja despesa mensal era de 70 mil réis, exatamente a quantia que eu ganhava lecionando História Universal no Ginásio Mineiro, do Dr. Carneiro a quem os estudantes apelidavam de Dr. Fecor. Era um magnânimo protetor dos estudantes pobres. Fiz na Faculdade mineira o $2^{\circ}$ ano de direito, obtendo em junho a nota plena. Por essa ocasiāo conheci um colega Riograndense, o Eduardo Lopes. Convidou-me ele a fazer o $3^{\circ}$ ano depois das férias, em exame vago, como permitia a Lei Rivadávia. Não me senti animado. Regressando porém a São João del-Rei, resumi várias páginas de Lafaiete (Direito da família e direito das cousas), li um pouco de Coelho da Rócha e folheei o Código criminal do Império.

Voltando a Ouro Preto fiz sentir ao Eduardo Lopes que não me sentia preparado. Ele porém insistiu, garantindo-me a aprovação. Aceitei afinal o convite, e entramos em exame. Ele que se achava tão seguro, só obteve a nota simples. A mim me plenificaram.

O $4^{9}$ ano correu sem dificuldades. A Faculdade tinha uma elite de professores ilustres: Augusto de Lima, David Campista, Afonso Arinos (o tio) Virgílio de Melo Franco, Levindo Lopes, Henrique Salles, etc.

As aulas de Augusto de Lima e as de Afonso Arinos eram magníficas.

Terminado o Curso, fugi para São João del-Rei, pois os companheiros queriam me indicar para orador da turma, o que absolutamente não me agradava.

\section{ESTREIA NO JURI.}

Estava eu no $4^{\circ}$ ano de direito quando fui a São João, em férias. La assisti a uma sessão do Juri, presidida pelo Dr. Ferreira e Costa : 
Mal tinha eu entrado na sala do Juri quando, por meio de um oficial de Justiça, recebi a ordem de ir falar ao Presidente. Obedeci e fui entender-me com o Dr. Ferreira e Costa. Disse-me ele que estava terminando um julgamento e que logo entraria um processo muito fácil. Era uma excelente ocasião de estreiar na tribuna de defesa e não admitia a minha recusa. Aguardei a nomeação e fui ouvir com atenção a leitura do proceșso.

Era um crime horrível. Um pretalhão mancomunado com uma negra, já de certa idade, matara-lhe o marido e os dois cumplices enterraram o cadaver na própria cabana em que viviam.

Ouvi a eloqüente acusação feita pelo Promotor ( $\mathrm{Dr}$ : Paulo Teixeira) e fiquei aterrorisado. Quando me foi dada a palavra articulei algumas palavras sobre crime passional, cousa que já havia estudado. Houve replica e treplica. O resultado é que o homem foi condenado a 30 anos de cadeia.

Consolei-me ao saber que, no juri seguinte, o réu foi defendido pelo Dr. Carvalho Mourão, mas a pena não fọi modificada.

\section{PROMOTORIA.}

Uma vez formado, pleiteei e obtive sem dificuldade a Promotoria de Monte Santo, no Sul de Minas.., Quando segui para lá passei por São Gonçalo de Sapucahy onde ainda viviam meu tio Joauqim (irmão de meu pai) e minha tia Carolina, irmã de minha avó paterna. Tio Joaquim morava na chácara onde ele e meu pai haviam nascido. Era ele já idoso. Mesmo assim prontificou-se a levar-me a cavalo até Monte Santo. Passamos por Varginha, Muzambinho, Guaxupé e Guaranésia. Foi uma longa viagem na qual tọo Joaquim muito me auxiliou.

Chegado a Monte Santo, hospedei-me no Hotel Sidalino.

Os vencimentos eram de 300 mil réis por mês; davam para pagar hotel, roupa e até algumas viagens ao Rio. E verdade que me apareceram algumas causas que me deram bastante dinheiro. Nas primeiras causas auxiliou-me o Dr. Wenceslau Bráz, excelente companheiro de fôro; dele me tornei amigo e the conservo muita gratidão.

Deixei a Promotoria para advogar. Em 11 de fevereiro de 1897 casei-me com a Srta. Maria das Dores de Freitas. Do nosso consórcio tivemos muitos filhos. Criamos e educamos a 16 deles. O mais velho é engenheiro Mário Lustosa, alto funcionário da Light, no Rio. O $2^{\circ}$ (Lauro) formou-se em direito, teve excelente advocacia em Carangola e lá se casou com a Srta. Maria Gonçalves (Espírito-santense). Tiveram uma filha - Stela Maria: — hoje casada com o. Sr. Almir Vieira, residente em Brasília. 
O Lauro faleceu em 1928, vítima do tifo que grassou em Carangola.

Outros filhos: José, Olavo, Irene, Laura, Afonso, Maria José, Custódio, Júlio, João, Emílio, Paulo, Lúcio e Maria Eugênia.

Além do Lauro, perdi já em Belo Horizonte, uma filha - Helena - vítimada pela schistosomose. Em 1929 faleceu minha Mãe.

\section{JUIZ DE DIREITO.}

Tendo-se aberto concurso, em Belo Horizonte, para o cargo de Juiz de Direito, nele me inscrevi, seguindo logo para a capital mineira.

Eramos 11 concurrentes. Cinco foram inabilitados. Dentre os 6 restantes consegui alcançar o $1^{9}$ lugar e fui nomeado para a comarca de Carmo do Parnaiba (1902). Para lá segui com a família: esposa e três filhos (Mário, Lauro e José). Fizemos 30 léguas a cavalo, pousando em fazendas e em ranchos. Quem hoje desfruta a comodidade do automóvel não pode fazer idéia do que sejam as dificuldades de uma tal viagem.

Carmo era uma cidade sertaneja: bom clima, boa água, bom povo e vida muito barata.

Os vencimentos eram de 500 mil réis mensais e o dinheiro dava de sobra.

O aluguel da casa custava 20 mil réis mensais. Surpreenderam-me os foguetes, por ocasião de minha chegada: os animais de minha comitiva se espantaram e receei por algum desastre com as crianças. Tudo acabou bem.

Instalei-me na casa já preparada e logo recebemos um lanche mandado por nosso vizinho, o Escrivão do crime, Sr. Edmundo Fontes dos Reis. Gostei do Carmo. Os campos em redor eram cobertos de cajú rasteiro, de mangabas e de outras frutas. Na cidade os teares de mão fabricavam colchas, toalhas e até peças de algodão e de lã para confecções:

Fôro quasi sem trabalho. Vida monótona.

Eu trazia a promessa de breve remoção e realmente, depois de um ano fui removido para a comarca de Leopoldina, onde cheguei em 1904.

\section{JUDICATURA EM LEOPOLDINA.}

Em Leopoldina havia dois chefes de política oposta: o Dr. Chagas (Rodolfo) e o Dr. Ribeiro Junqueira. Ambos me ofereceram hospedagem.

Preferi o hotel. Pouco depois montei casa e fui buscar a família. Exerci a judicatura em Leopoldina durante 23 anos. Lá me nasceram todos os filhos à exceção dos 3 primeiros de que já falei. 
Além dos trabalhos de Juiz, lecionei no Ginásio Leopoldinense, Português, História Universal e Psicologia. Tomei parte também nas bancas examinadoras de Latim e Grego.

Lá consegui fundar a Biblioteca Leopoldinense que foi útil a muitos Leopoldinenses. Dos meu alunos de então acham-se no Tribunal de Justiça do Estado, os seguintes: José Alcides Pereira, Welington Brandão, Garcia Forjás e Antônio Pedro Braga. São também do meu tempo no ginásio, o Senador Milton Campos e o Dr. Flávio Nelson de Sena. Foram diretores do ginásio o Engenheiro Dr. Henrique Cruz, o Dr. Jacques Maciel o Sr. Botelho Reis e o Dr. Carlindo Mairink, hoje Juiz Municipal em Belo Horizonte. Na judicatura não tive muito trabalho. Apenas em certa ocasião estivemos sob a ameaça de um grande conflito. Era então redator da "Gazeta Leopoldinense" o Farmacêutico Leite Guimarães que atacou fortemente os adversários do Dr. Ribeiro Junqueira. A reação foi formidável. Entretanto, com a prudência do Senador Botelho e do Dr. Randolfo Chagas, conseguimos evitar o conflito.

Durante o meu tempo em Leopoldina inaugurou-se o Ginásio, o Forum, a Santa Casa, o Cinema e outros benefícios que reanimaram a cidade. Quando lá cheguei ainda se faziam sentir os efeitos da febre amarela que estava aniquilando o Brasil. Bendito Osvaldo Cruz!

Dentre os advogados do fôro Leopoldinense quero salientar o Dr. Alberto Moretzsohn, o Dr. Tavares de Lacerda, o Dr. Ribeiro Junqueira, o Dr. Antônio Augusto Teixeira, o Dr. Randolfo Chagas e o Dr. Artur Leão.

Recebi do povo Leopoldinense duas grandes distinções: um anel de grau e uma beca de Juiz. Deixei com saudade a comarca onde servi por tantos anos. Eu não poderia recusar a promoção para Juiz de Fora. Lá me empossei em 1927.

\section{JUIZ DE FORA.}

O fôro de Juiz de Fora era de elevada cultura. Lá encontrei como advogados Constantino Paleta, Antônio Augusto Teixeira, Eduardo Menezes, Luiz Paleta, Sadi Carnot, Rafael Cirigliano, Francisco Sales de Oliveira e outros. Fora meu antecessor o Dr. Cesar Franco. Desanimado de encontrar curadores para numerosos presos que desde muito aguardavam julgamento, tive de enfrentar este problema. Mandei organizar uma lista dos advogados por ordem de antigüidade: Era decano o Dr. Constantino Paleta, antigo Constituinte de Minas e nome de grande projeção na cidade. Fiz-lhe uma visita e mostrei que, si ele aceitasse a 1a. curatela, ninguém mais poderia recusar a defesa dos outros réus. Assim é que pude levar a termo os julgamentos.

Em Juiz de Fora lecionei literatura e direito comercial na Academia de Comércio. 
Com o financiamento do Dr. José Procópio, construi uma casa que tive de vender quando transferido para Belo Horizonte. Gostei de Juiz de Fora. A Rua Halfeld é uma espécie de salão onde todos se cumprimentam e trocam dedos de prosa. Isto contribue para um grande convívio social. O Juiz Municipal era o Dr. Hugo Andrade.

Sua principal tarefa consistia em rubricar livros comerciais, serviço muito rendoso.

O Escrivão do Crime era funcionário muito perito, de sorte que auxiliava eficazmente no serviço criminal. O Promotor de Justiça era o Dr. Luiz Detsi. Estava eu em Juiz de Fora quando se formou em medicina meu filho Olavo, que lá ficou como pediatra.

Estava também na Escola de medicina meu filho Afonso, hoje médico em Quatis de Barra Mansa.

Foi curta a minha permanência em Juiz de Fora, pois o governo Antônio Carlos me designou Procurador Geral do Estado (1930). Tive bastante serviço na Procuradoria. No ano seguinte o Dr. Olegário Maciel me nomeou Desembargador. 'Aposentei-me em 1934.

Nota - Quando eu estava em Juiz de Fora (1928) faleceu, em minha residência, meu filho Lauro que viera doente de Carangola onde mantinha próspero escritório de advocacia. Iniciou-o no fôro de Carangola o Dr. José Ribeiro de Miranda, cuja amizade conservo com profunda gratidão.

\section{ALGUNS JULGAMENTOS.}

Durante o meu tempo de Desembargador proferi muitos julgamentos. De dois deles ficou-me funda impressão. O 19 se deu quando em 1931 (salvo erro) se deu a chamada revolta dos estudantes. E que o Dr. Francisco Campos, então Ministro de Getúlio Vargas; resolveu permitir aos estudantes a aprovação por decreto. A Universidade de Minas, que gozava de autonomia e era dirigida pelo Dr. Mendes Pimentel, entendeu de exigir exames.

Os estudantes assistindo à reunião da Congregação, ficaram indignados e prorromperam em vaias. Um deles levantou-se e se dirigiu à Mesa que presidia a reunião. Um dos filhos do Dr. Pimentel, supondo talvez que seu pai ia ser agredido, desfechou um tiro contra esse estudante. Os outros, revoltados desceram as escadas da Faculdade e barraram a saída dos lentes. Três desses estudantes vendo na Praça um automóvel do Dr. Camilo Pimentel, trataram de incendiá-lo. O Dr. Camilo, da sacada da Faculdade, alvejou esses estudantes a tiro. 
Feito o processo o Juiz de Direito (Dr. Amorim) absolveu o acusado sumariamente e o Tribunal confirmou a sentença. Fui o único voto vencido. Pareceu-me que o Dr. Camilo não tinha direito de alvejar os estudantes. $O$ automóvel estava na praça pública, entregue portanto à vigilância da polícia que teria de indenisar o dano causado.

Demais a violência dos estudantes era até certo ponto excusável, de vez que um de seus colegas tinha recebido tiros dentro do salão da Faculdade.

Si a absolvição fosse proferida pelo juri, eu concordaria. A absolvição sumária pareceu-me um favor do Juiz de Direito.

O outro julgamento que me impressionou foi o caso de um protesto por novo julgamento recurso que era facultado ao réu quando a pena era de 20 anos ou mais.

Da ata constava que havia sido interposto o recurso, mas este não fora tomado por termo. O Tribunal resolveu não conhecer do recurso e mandou que o réu cumprisse a pena. Discordei. O termo, de vez que o recurso constava da ata, era desnecessário. Demais, se não foi lavrado o termo, a culpa era do Escrivão e não do réu que se achava dentro da prisão. Parece-me que eu estava com a razão, porque em o novo Código do Processo foi abolido o inútil termo de protesto.

\section{NOTAS FINAIS.}

Tendo me aposentado em 1934, lecionei psicologia no Curso anexo da Escola de Farmácia (Belo Horizonte). Era diretor da Faculdade meu primo Dr. Roberto de Almeida Cunha, casado com a conhecida professora Maria Luiza de Almeida Cunha.

Nesse curso pareceu-me que já começara a decadência do ensino. A cola era uma instituição, apesar da vigilância que eu procurava exercer. Vindo a reforma Capanema, o Curso foi extinto e eu fiquei em plena inatividade. Divertia-me apenas um pequeno grupo de colegas. Reuniamos os companheiros em qualquer ponto da cidade e aí comentavamos política, contavamos pilhérias e novidades que encontravamos nos jornais.

Desse grupo faziam parte o Desembargador Gentil Rangel, seu irmão o eminente escritor Godofredo Rangel, o Dr. José Moreira, o Desembargador Júlio Gorgulho e outros. O grupo continua, mas eu com 85 anos e a vista avariada poucos vezes lá apareço

Alegram-me as visitas que os filhos me costumam fazer anualmente, entristecem-me as doenças que, de vez, em quando, os afligem. 
FAMILIA LUSTOSA.

Recomposição bibliográfica e novas informações escritas em diversas datas, ate os 95 anos de idade.

O casal João Batista Pimentel Lustosa teve 12 filhos.

Um (Artur) faleceu aos 14 anos, outro (Luiz aos 22 anos).

Os demais sobreviveram até idade mais ou menos avançada.

O primeiro a falecer foi o Dr. Joaquim Lustosa, engenheiro de Minas. Foi o grande incentivador da exploração de Manganês em Lafaiete (Morro da Mina) Terminada a 1a. grande guerra foi vendida a mineração por 25.000 contos, tendo o Joaquim uma pequena porcentagem. Isso the permitiu comprar uma boa casa no Rio; com grande chácara e onde construiu uma vila. Pouco depois aceitou a presidência das Minas de Carvão em São Jerônimo (Rio Grande do Sul). Estava ele nessa direção, no Rio, quando um dia se sentiu mal. Saiu do escritório, tomou um taxi e dirigiu-se para o Hospital São José. Lá chegando mandou chamar o genro (Comandante Aragão). Quando este chegou já o Joaquim tinha falecido.

O $2^{\circ}$ a falecer foi o Dr. Carlos Lustosa, ortodondista que deixou grande renome. Era quase surdo. Apesar disso falava bem o francês e o inglês e fez o curso de ortodontia na América do Norte. Em virtude da surdez não ouviu o barulho de um bonde que se aproximava e foi por ele esmagado no Largo da Glória (Rio de Janeiro).

A $3^{\text {a }}$ vítima foi a mais nova - Maria - que faleceu solteira em Belo Horizonte, em casa de meu mano Sabino.

A 4a a falecer foi Laura, Irmã Vicentina, que por muitos anos serviu no Hospital de Diamantina.

Em 1959, já com 87 anos de idade, faleceu o Sabino, desembargador aposentado do Tribunal de Minas. Viveu muito mais para o próximo do que para si mesmo.

Restamos - eu - minha irmã Adelina (viuva de Dr. Luiz Andrade) D. Antônio Lustosa (arcebispo de Fortaleza) e o Dr. Paulo Lustosa, fabricante da "Cêra Dr. Lustosa", em São João del-Rei.

Certamente eu, como mais velho, serei chamado mais cedo para prestar as eternas contas. 


\section{FAMILIA CUSTODIO LUSTOSA.}

Eu e minha mulher criamos e educamos 16 filhos. E não falo de 2 que morreram pouco depois do nascimento, nem de um $3^{\circ}$ que faleceu com um ano e meio, provavelmente de gastro-enterite.

Dos 16 que chegaram à idade adulta o primeiro a falecer foi o Lauro Formado em direito, com excelente escritório de advogacia em Carangola, foi vítima do tifo em 1928, quando grassou um surto epidêmico naquela cidade mineira. Deixou viuva (Maria Gonçalves) e uma filha Stela Maria, esta hoie casada com o Sr. Almir Vieira e reside em Brasília.

A $2^{\text {a }}$ a falecer foi Helena, solteira, muito religiosa. As companheiras na Ação Católica de Belo Horizonte perstarem-lhe comovida homenagem.

O $3^{\circ}$ falecimento foi de Maria José, que era casada com o Dr. Tito Botelho Martins. Deixou 3 filhos. Maria era admirável: paciente, alegre, excelente esposa e mãe de família.

Falemos dos vivos. O mais velho é o Mário, engenheiro eletricista e com alta colocação na Light (Rio). O $2^{\circ}$ José é comerciante no Rio. Casou-se em Cámpos com D. Zuleika Dias Ferreira. O $3^{\circ}$ é o Olavo, médico pediatra em Juiz de Fora, com grande clínica. Casou-se com D. Carmen Leal e tem 7 filhos. O $4^{\circ}$ é o Afonso - médico e fazendeiro em Quatis de Barra Mansa. Casou-se com D. Emiliana Marcondes. Tem 2 filhos.

O $5^{\circ}$ é o Júlio, dentista e ortodontista em Petrópolis. Casou-se com D. Brasília Dolne. Tem 5 filhos. O 6\%. (Aqui há uma inversão. Mais velho do que o Júlio é o Custódio, advogado em Belo Horizonte e casado com D. Lígia Castro). $7^{\circ}$ João Lustosa( advogado em Leopoldina. $8^{\circ}$ Emílio, engenheiro em Volta Redonda. $9^{\circ}$ Paulo, funcionário de Justiça eleitoral (Belo Horizonte) $10^{\circ}$ Lúcio - advogado em Lafaiete. Das filhas vivas noto: Irene, professora, solteira, reside comigo. Laura - Casada com o Dr. Joaquim Junqueira, reside em Leopoldina. Maria Eugênia - casada com o Dr. Paulo Emílio Rubião, reside em Belo Horizonte.

\section{GENEALOGIA.}

Meus avós: Sabino de Almeida Magalhães e Delfina Leocádia Leite Magalhães.

Meus tios filhos de meu avô: Guilherme de Almeida Magalhães, Francisco, Carlos, Eugênio, Augusto, Sabino, Eduardo, Constança, Amélia e Luis. Minha mãe, Delfina de Almeida Lustosa, fazia parte dessa numerosa família.

Meus primos, filhos de uma irmã de minha avó (Mariana): Gabriel, João Páulo, Eduardo, Custódio. 
Uma parenta de minha avó, casou-se em Mar de Hespanha dando origem à família Magalhães Pinto a que pertenceu o Dr. Estevão de Magalhães Pinto. O Dr. José de Magalhães Pinto presidente do Banco Nacional não pertence a esta família.

\section{NOTAS AVULSAS ENCONTRADAS NO FIM DO CADERNO.}

\section{VENDA DE UMA FAZENDA.}

Quando era eu Promotor em Monte Santo de Minas, recebi a incumbência de vender uma grande fazenda pertencente à minha família. Situava-se no Município de Sacramento, limite do Município de São Roque. Para ir até lá tive de ir a Passos, atravessando de barca o Rio Grande, passando pelo distrito de Ponte Alta e subindo custosamente a Serra das Sete Voltas. Tão cansado cheguei à primeira fazenda além da serra, que não pude chegar às terras que tinha de vender. Mandei chamar o comprador e combinamos o preço (cinco contos de réis por uma fazenda de mil alqueires). Fixamos a data de encontro em. Sacramento, onde devíamos passar a escritura. Lá fui eu. Para ir da estação à cidade havia uma ponte que ruira. Estava em reconstrução e os alicerces estavam a meio metro abaixo das águas. Eu tinha de passar a cavalo sobre esse alicerce, se não eu teria de fazer um contôrno de 2 léguas. Preferi arriscar-me... Passei felizmente e fui à cidade onde passei a escritura entregando as 30 procurações que levava.

Fiquei encantado com a cidade de Passos. Vasta, com excelente carne e magnífico peixe (Dourado) que o Rio Grande oferecia sem muita relutância. No distrito de Ponte Alta notei que a estrada estava péssima, mas o hospedeiro me fez saber que o $\mathrm{Sr}$. Coronel não gostava que se falasse nisso.

A cidade de Passos era dominada pela dinastia dos Medeiros. Conheci o chefe, Cel. Zeca Medeiros. Era, aparentemente, um homem gentil, mas dizem que não tolerava a menor desobediência às suas ordens. Ele e alguns de seus companheiros foram liquidados a bala, quando enfrentaram um delegado, procurando embaraçar um processo policial.

\section{UMA VIAGEM.}

Ainda durante a minha Promotoria em Monte Santo tive de fazer uma viagem a São Sebastião do Paraiso. Foi em agosto de 1896(?). O frio era impiedoso, mas apesar disso puz-me a caminho. Ao chegar a São Sebastião (8 léguas de viagem) era tal o meu regelamento que não pude descer do animal. Desceram-me e envolveram-me em cobertores até que a circulação se regularisasse.

Lembro-me de que nessa ocasião tive uma terrível dor de dentes. Fui ao único deñtista da cidade. Era uma senhora e talvez por isso, não conseguiu 
extrair-me o dente, deixando-me em piores condições. Voltando a Monte Santo, fui a um dentista menos inábil que conseguiu extrair o molar infectado com grande abcesso.

Lembro-me agora de falar de uma outra extração que fiz em São João del-Rei. O dentista era muito competente (Dr. Antenor Reis), mas resolveu fazer a extração sem anestesia. Sofri muito, é claro: mas o hábil dentista, contando pilhérias, fez-me suportar a operação e conseguiu extrair o dente sem maiores complicações. Foi ao que parece, uma extração psicológica.

\section{MINHA VIDA EM OURO PRETO.}

Quando cheguei a Ouro Preto para continuar os estudos de Direito (que havia começađo no Rio) já estudava, na antiga capital de Minas, meu mano mais velho (Joaquim). Era ele muito relacionado não só com a classe acadêmica como ainda entre famílias Ouropretanas. Foi fácil aproveitar-me dessa popularidade e conseguir boa apresentação em vários salões familiares. Os estudantes de bom comportamento eram bem recebidos em toda a parte. Tínhamos assim danças, recitativos, boa prosa etc. Tive então ocasião de conhecer o poeta Raymundo Correia, o escritor Afonso Arinos e seu irmão Afrânio com quem me encontrava sempre na secretaria da Faculdade de Direito. Conheci ainda Augusto e Bernardino de Lima, Costa Sena, Silviano Brandão, Virgílio de $\mathbf{M}$. Franco etc. Durante minha estadia em Ouro Preto, levantou-se a estátua de Tiradentes, sendo orador, por parte dos estudantes, o acadêmico Silvino dos Mares Guião. Era diretor da Secretaria do Interior o Dr. Teófilo Ribeiro, sendo Presidente do Estado o Dr. Afonso Pena.

$O$ que mais me encantou em Ouro Preto foi o seu esplendido luar. Isso explica as poesias de Cláudio, Gonzaga e Alvarenga. Apreciei também as serenatas que inspiravam magnífico soneto de Augusto de Lima. Foi meu contemporâneo na Faculdade o grande poeta Alfonsus Guimarães.

Lecionei no Colégio Mineiro (do Dr. Carneiro) a cadeira de História Universal. Assistiu a algumas de minhas aulas o Nelson de Sena ainda (estudante).

O compendio adotado era a História Universal de Consigleri Pedroso.

A república em que moravamos, ficava-me em 70 mil réis por mês, exatamente o que eu ganhava como professor. Lentes de Faculdade: Augusto de Lima, David Campista, Mello Franco, Henrique Sales, Sabino Barroso, Levindo Lopes, Bernardino de Lima e outros.

Meu colega Eduardo Lopes obrigou-me a fazer exame vago do $3^{9}$ ano. Felizmente consegui ser plenificado. 
Tirado o meu diploma, fui entender-me com o Dr. Silviano Brandão, Secretario do Interior. Daí vem a minha nomeação para Promotor da Comarca de Monte Santo.

\section{TRES CARTAS ESCRITAS A UM NETO, JA AOS 95 ANOS.}

Carlos David. Belo Horizonte, 7 de junho de 1969. Recebi e agradeço o seli jornal, o "Quetzal". Custei a perceber o nome do jornal. Não sei onde voces o encontraram. Se eu fosse o consultado proporia "A espiral" para signifjcar que a juventude dá muitas voltas, mas sempre para o alto. Aqui vai um caso pessoal: Quando aluno do Pedro II, tive também com vários colegas, um jornalzinho. O lema era este: "Debelar os soberbos, empenhar para isso a própria vida". Veja você a nossa petulância. Aos 14 anos já queríamos reformar o mundo! Isto me anima confiar na juventude. Encontrei no seu jornal muitas informações interessantes e admirei a iniciativa que voces tiveram: papelaria, loja, Banco, as sementes de futuros industriais. Prossigam, mas sem fazer guerra aos velhos. Parabens. Recomendações do avô e amigo. C.L.

Carlos David. Saudações (1969). Voce me fez perguntas sobre Tuiutí e agora a Abolição. Vou dizer alguma cousa. Note, porém, que escrevo de memória porque minha vista não me permite consultar a nenhum livro. - Em Tuiutí houve duas batalhas, a $1^{\text {a }}$ em 24 de maio de 1864, na qual o grande heroi foi o general Osório (marquês de Herval). Na $2^{\text {a }}$ batalha o comandante foi o Conde de Porto Alegre (Manoel Marques de Sousa). Em ambas as armas brasileiras mostraram grande heroismo. Sobre a Abolição escrevo com mais facilidade. Eu tinha 15 anos quando foi sancionada a lei da Abolição. $O$ imperador estava viajando pela Europa e em lugar dele era o Brasil governado pela princesa Isabel. Foi essa princesa, filha de D. Pedro II que sancionou a lei. A opinião pública estava preparada pelo partido abolicionista, principalmente pelos oradores José do Patrocínio, Joaquim Nabuco e Afonso Celso. Em São Paulo os negros fugiam em massa e o Exército se recusava capturá-los.

O partido escravocrata, chefiado pelo Barão de Cotegipe, foi vencido. Assim pois a Abolição foi recebida entre flores. O povo brasileiro sentiu uma grande alegria por se ver assim integrado na civilização. Note-se que os versos de Castro Alves muito contribuiram para a propaganda abolicionista, principalmente a poesia "O navio negreiro". José do Patrocínio, o grande orador, era negro, filho de uma escrava, mas de uma eloqüência arrebatadora. E o que me ocorre dizer. Recomendações e abraços. Avô e amigo. C.L. 
Belo Horizonte, 19-4-69.

Recebi sua carta trazida pela Mariza. Tenho a dizer primeiramente que voce usa, para comigo, uma linguagem muito derramada, isto é, com muitos elogios. Isto não me serve, quero ser tratado como camarada. Vai em seguida uma notinha sobre Tiradentes que considero meu conterrâneo. Nada mais. Voce está vendo que eu mal... posso escrever. A vista não me ajuda. (Parabens pelo resultado da eleição (para presidente do Clube do Colégio). Avô e amigo. C. Lustosa.

Tiradentes: Joaquim José da Silva Xavier nasceu na fazenda do Pombal: Essa fazenda ficava na linha limítrofe entre as cidades de São João e São José del Rei. Tem-se entendido que a terra de Tiradentes é São José. Entretanto, o historiador Basílio de Magalhães mostrou que naquele tempo a fazenda do Pombal pertencia a São João del Rei. Por isso me considero conterrâneo de Tiradentes. Sei que Tiradentes estudou em São João. Conheci sobrinhos-netos de Tiradentes. Eram claros, perfeitamente arianos. E só. C.L. - P.S. Em Viçosa (MG); Tiradentes impediu que um português batesse em seu escravo. Aquele reclamou do delegado e Tiradentes foi preso. C.L. (***).

$(* * *)$. - Ainda se tem notícia de capítulos, cerca de 50 páginas datilografadas que, destinadas aos alunos do Ginásio Leopoldinense, onde o Dr. Custódio Lustosa, então Juiz de Direito em Leopoldina (MG), lecionou, durante duas décadas dentre outras disciplinas, História Universal; poderiam ser analisados, em nível comparativo, pelos especialistas em livros didáticos (M.R.). 